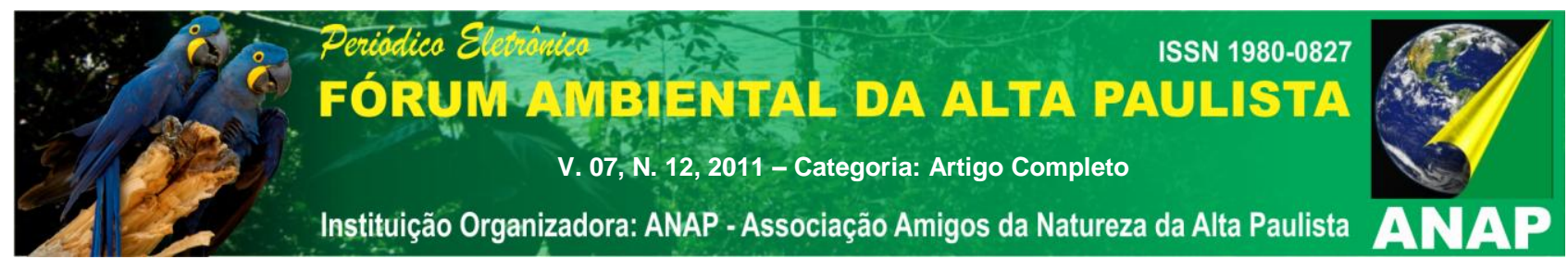

\title{
REMOÇÃO DE NITROGÊNIO AMONIACAL EM UM REATOR BIOLÓGICO OPERADO COM BAIXAS CONCENTRAÇÕES DE OXIGÊNIO DISSOLVIDO
}

\author{
Kiemi de Brito Murata ${ }^{1}$ \\ Carla Eloísa Diniz dos Santos² \\ Francisco Javier Cuba Terán ${ }^{3}$
}

RESUMO: Este trabalho tem como objetivo verificar a oxidação anaeróbia de amônia em efluente de abatedouro bovino, estabelecendo inicialmente o enriquecimento de microorganismos anaeróbicos oxidadores de amônia (Anammox) aderidos em meio suporte. Desta maneira, foi construído um reator biológico de leito fixo e fluxo ascendente, que conta com um sistema de bombeamento do resíduo através do material suporte, sendo que este último tem a função de oferecer condições para uma maior retenção de biomassa bacteriana. Foi utilizado como inóculo o lodo de uma lagoa de estabilização anaeróbia de um frigorífico localizado no município de Presidente Prudente-SP. Para os estabelecimento da cultura de bactérias anaeróbias foi utilizado o meio de cultura sintético descrito por MARTINS (2007). Como resultado pôde-se notar a remoção de $\mathrm{N}$-amoniacal em todas as bateladas realizadas e também o consumo do nitrito afluente combinado a uma estabilidade nas concentrações afluente e efluente de nitrato. Através dos testes termogravimétricos, pôde-se inferir há uma tendência a presença de material bacteriano agregado ao meio suporte, indicando também o favorecimento à cultura Anammox no sistema em questão.

Palavras-chave: Anammox; reator anaeróbio; nitrogênio amoniacal.

\footnotetext{
${ }^{1}$ Graduanda em Engenharia Ambiental, Universidade Estadual Paulista “Júlio de Mesquita Filho" - Faculdade de Ciências e Tecnologia, campus de Presidente Prudente. E-mail: kiemimurata@gmail.com.

2 Graduanda em Engenharia Ambiental, Universidade Estadual Paulista “Júlio de Mesquita Filho" - Faculdade de Ciências e Tecnologia, campus de Presidente Prudente. E-mail: carla_dds@hotmail.com.

${ }^{3}$ Engenheiro Civil, com mestrado e doutorado na área de Hidráulica e Saneamento e pós-doutorado em Engenharia Urbana. Professor da Universidade Estadual Paulista "Júlio de Mesquita Filho" - Faculdade de Ciências e Tecnologia, campus de Presidente Prudente. Email: fteran@fct.unesp.br.
} 


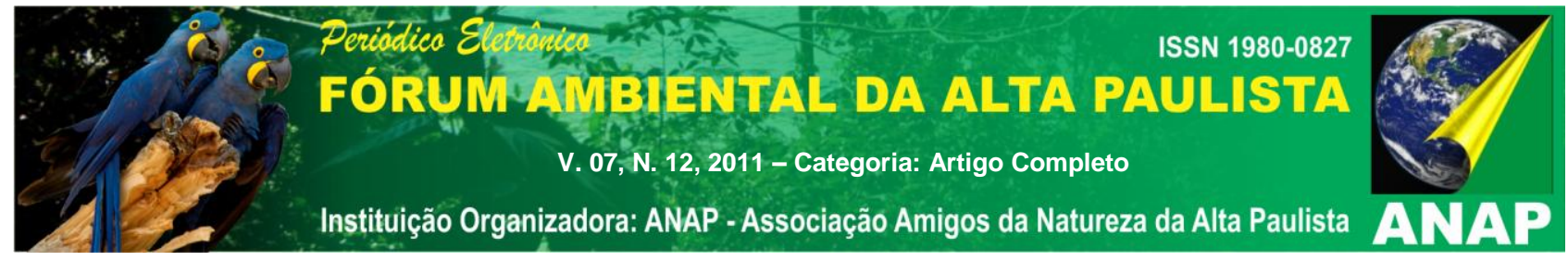

\section{Introdução}

A temática ambiental tem se destacado em nossa sociedade face ao alto impacto que as mais distintas atividades humanas têm causado sobre o ambiente, trazendo como consequência a exaustão de muitos recursos naturais (SCHIERHOLT NETO, 2007). O desenvolvimento da sociedade tem alterado os produtos, as formas de produção e os resíduos gerados, este ritmo esta trazendo passivos ambientais que devem receber atenção, pois graves problemas ambientais podem ser gerados.

Para tentar diminuir os impactos ambientais sobre o meio ambiente, muitas técnicas de tratamento visando a remoção de matéria orgânica de águas residuárias foram desenvolvidas e implementadas. Porém, a remoção de nutrientes (nitrogênio e fósforo) não recebeu a mesma atenção, se tornando uma área carente de informações e técnicas viáveis para sua implantação.

Dentre as formas nitrogenadas que aparecem no efluente final de um frigorífico, destacam-se o nitrogênio amoniacal, o nitrito e o nitrato. O primeiro é altamente tóxico e possui uma grande demanda por oxigênio dissolvido, sendo o principal responsável pela eutrofização dos corpos d'água (BOAVENTURA et al, 1997). Além disso, sob o ponto de vista de saúde pública, o nitrogênio é o agente causador da metahemoglobinemia (síndrome do bebê azul) e também é o responsável pela formação de substâncias de poder mutagênico e carcinogênico em diversos organismos.

Diante da necessidade de cumprir normas ambientais e melhorar a qualidade dos recursos hídricos disponíveis, várias técnicas de tratamento terciário (degradação de fósforo e nitrogênio) vêm surgindo. No entanto, boa parte destes tratamentos gera custos adicionais de implantação e operação do sistema, razão pela qual há grande interesse no desenvolvimento de tecnologias que minimizem esses custos (NOCKO, 2008).

Assim, este trabalho tem como objetivo principal estabelecer o enriquecimento de microorganismos anaeróbios oxidadores de amônia (Anammox) para efetuar a remoção de nitrogênio amoniacal em águas residuárias geradas em indústrias de abate de bovinos por meio de um reator biológico de leito fixo e fluxo ascendente. 


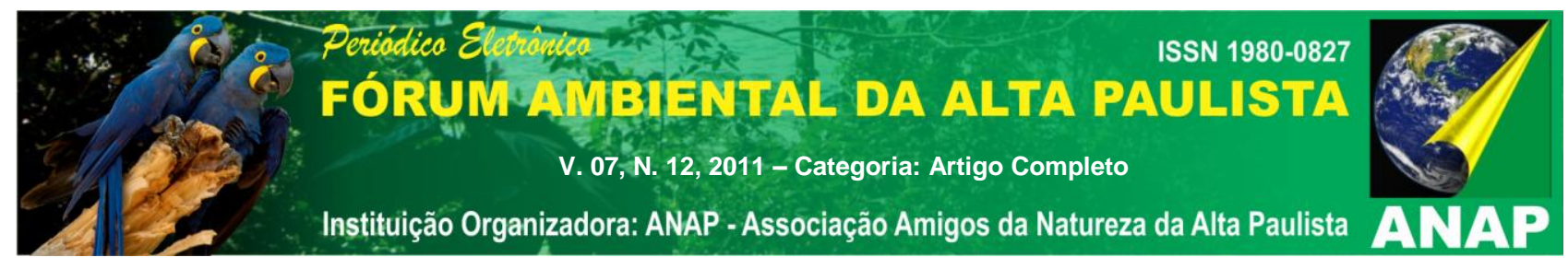

\section{Revisão Bibliográfica}

A lei federal no 9433, de 8 de janeiro de 1997, que institui a Política Nacional dos Recursos Hídricos e o Sistema Nacional de Gerenciamento dos Recursos Hídricos, estabelece dentre outros aspectos que:

I - a água é um bem de domínio público;

II - a água é um recurso natural limitado, dotado de valor econômico;

III- a gestão dos recursos hídricos deve sempre proporcionar o uso múltiplo das águas.

Assim, pode-se afirmar que a água é um bem que deve estar disponível a todos e, por se tratar de um recurso de disponibilidade finita, deve atender as diversas atividades humanas de maneira racional e eficiente. Porém, é cada vez pior a situação da água disponível no planeta já que, segundo Merten et al. (2002), sua qualidade vem sendo comprometida em decorrência da poluição causada por diferentes fontes, tais como: efluentes domésticos, efluentes industriais e o deflúvio superficial urbano e agrícola; sendo que os esgotos - industriais e domésticos - estão entre as principais fontes de poluição dos corpos d'água.

A presença de nitrogênio e fósforo em águas residuárias é inevitável; porém isso se torna um problema, quando estes componentes atingem os corpos d'água em concentrações acima do permitido pela legislação ambiental vigente. No Brasil, a Resolução CONAMA № 357, de 17 de março de 2005, que estabelece as condições e padrões de lançamento de efluentes, fixa o limite máximo de emissão apenas para o nitrogênio amoniacal, por ser esta a forma mais nociva ao meio ambiente, em 20 mg de $\mathrm{N}-\mathrm{NH}_{4}{ }^{+} \cdot \mathrm{L}^{-1}$. Entretanto, em termos de padrões de lançamento de efluentes, não houve nesta atualização da legislação a preocupação em se limitar a descarga de outras formas de nitrogênio, como o nitrato e o nitrito, que também oferecem riscos de contaminação ambiental (PHILIPS, 2008). Por outro lado, deve-se ressaltar que esta resolução apresenta valores permissíveis de concentração de nitrito e nitrato, para padrões de qualidade da água, de acordo com o enquadramento em classes dos corpos hídricos.

Existe também o problema de saúde pública ligado ao saneamento dos domicílios, uma vez que os reservatórios utilizados para abastecimento público estão sujeitos à proliferação excessiva de cianobactérias, devido à alta concentração de compostos 


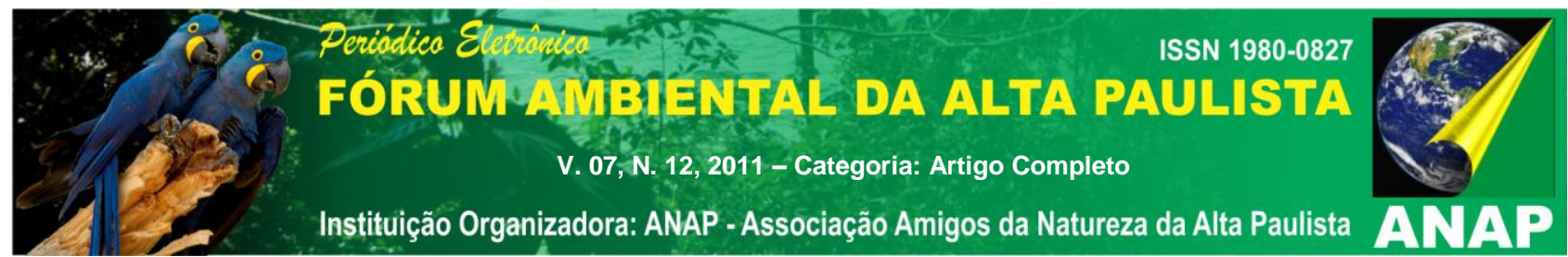

nitrogenados provenientes da falta de tratamento adequado dos despejos domiciliares e industriais. Algumas dessas algas podem sintetizar cianotoxinas tais como: as hepatotoxinas (microcistina e nodularina), as neurotoxinas (anatoxina-a, anatoxina-a(s), homoanatoxina-a e saxitoxina) e uma dermatoxina (lingbiatoxina) (CODD et al., 2005). Estas cianotoxinas são perigosas porque, quando presentes na água utilizada para abastecimento, pesca ou lazer, podem atingir as populações humanas e provocar efeitos adversos como gastroenterite, hepato-enterite e outras doenças do fígado e rim, câncer, irritações na pele, alergias, conjuntivite, problemas com a visão, problemas respiratórios, asfixia, convulsões e morte, dependendo do tipo da toxina, da concentração e da via de contato (KUIPER-GOODMAN et al., 1999).

Outro problema que pode ser evitado através da remoção de compostos nitrogenados nas águas residuárias é a metahemoglobinemia - também conhecida como doença do bebê azul - doença caracterizada pela conversão da hemoglobina em metahemoglobina em grande quantidade, a qual é incapaz de se ligar ao oxigênio e transportá-lo aos tecidos, causando assim, a má oxigenação das células, o que pode levar à morte dos pacientes.

Entre os processos conhecidos para a remoção de compostos nitrogenados, o biológico é o que melhor se adapta à realidade econômica e ambiental de muitas indústrias (EPA, 2002 apud KHIN \& ANNACHHATRE, 2004), por ser mais seguro e barato. Este método baseia-se nos processos de nitrificação e desnitrificação.

A nitrificação é um processo que ocorre em vários ambientes naturais e é descrita por duas etapas (Equações 1 e 2). As bactérias responsáveis por esta reação são bactérias aeróbias quimiolitoautotróficas, isto é, obtém energia para as suas funções vitais da oxidação de um composto inorgânico, no caso amônio ou nitrito e utilizam como fonte de carbono apenas o carbono inorgânico (MADIGAN et al., 1997).

$$
\begin{aligned}
& 2 \mathrm{NH}_{4}^{+}+3 \mathrm{O}_{2} \rightarrow 2 \mathrm{NO}_{2}^{-}+4 \mathrm{H}^{+}+2 \mathrm{H}_{2} \mathrm{O}+\text { Energia } \\
& 2 \mathrm{NO}_{2}^{-}+1 \mathrm{O}_{2} \rightarrow 2 \mathrm{NO}_{3}^{-}
\end{aligned}
$$




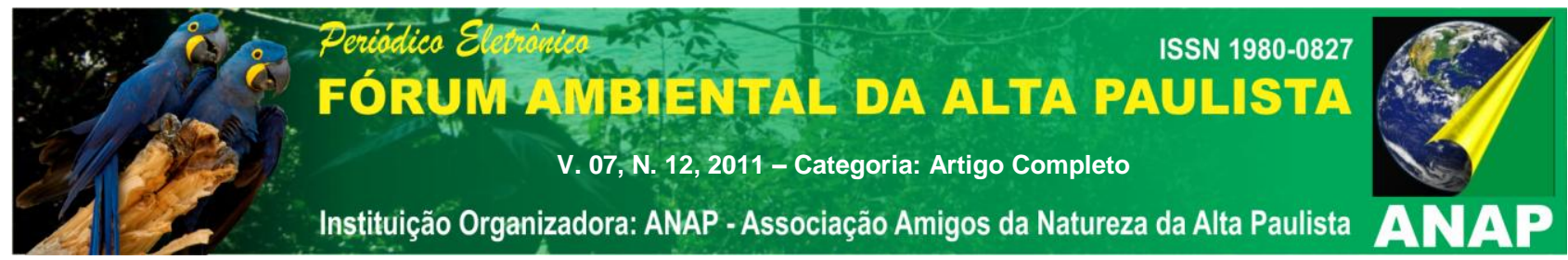

A conversão biológica de compostos oxidados de nitrogênio como nitrito e nitrato em compostos mais reduzidos como óxido nítrico (NO), óxido nitroso $\left(\mathrm{N}_{2} \mathrm{O}\right)$ e gás nitrogênio $\left(\mathrm{N}_{2}\right)$ é denominada desnitrificação e é caracterizada pela ação de bactérias heterotróficas facultativas. Segundo Metcalf \& Eddy (2003 apud BRITO, 2008), a equação de desnitrificação do efluente a partir de fontes de nitrato é:

$$
\mathrm{C}_{10} \mathrm{H}_{19} \mathrm{O}_{3} \mathrm{~N}+10 \mathrm{NO}_{3}{ }^{-} \rightarrow 5 \mathrm{~N}_{2}+10 \mathrm{CO}_{2}+3 \mathrm{H}_{2} \mathrm{O}+\mathrm{NH}_{3}+10 \mathrm{OH}^{-}
$$

A presença de matéria orgânica é essencial para que o processo de desnitrificação ocorra, já que esta funciona como doadora de elétrons. Ela pode ser suprida através de compostos sintéticos adicionados ao meio ou, pela matéria orgânica presente no próprio resíduo a ser tratado (SCHIERHOLT NETO, 2007). O oxigênio pode causar inibição na desnitrificação pela repressão das enzimas redutoras de nitrato. Contudo, a desnitrificação pode ocorrer na presença de baixas concentrações de oxigênio dissolvido $\left(0,5 \mathrm{mg} \mathrm{O}_{2}\right.$. $\left.\mathrm{L}^{-1}\right)$. Isso porque a concentração de oxigênio no interior do floco ou biofilme pode ser menor que no meio líquido, promovendo a desnitrificação nesses locais (METCALF \& EDDY, 2003).

Segundo Mulder et al. (1995), na década de 90 um processo alternativo de remoção de $\mathrm{N}$-amoniacal foi descoberto enquanto alguns pesquisadores observavam a perda de amônio em um reator desnitrificante em uma estação de tratamento de esgotos na Holanda. O microrganismo responsável pela transformação anaeróbia de amônio em nitrogênio gasoso era desconhecido, porém, Strous et al. (1999) identificaram o mesmo como uma bactéria autotrófica da ordem Planctomycetales e o processo foi chamado de Anammox ("Anaerobic Ammonium Oxidation"). A bactéria Anammox converte a amônia diretamente em gás nitrogênio usando o nitrito como aceptor final de elétrons e o carbono inorgânico como fonte de energia para seu o crescimento, sob condições anóxicas. Desde que ela foi descoberta, o processo Anammox tem sido apontado como uma forma economicamente eficiente e sustentável de tratar águas residuárias ricas em nitrogênio amoniacal (JETTEN et al., 1997; KARTAL et al., 2010).

Segundo Van de Graaf et al. (1996), a estequiometria global de um processo Anammox pode ser descrita da seguinte maneira: 


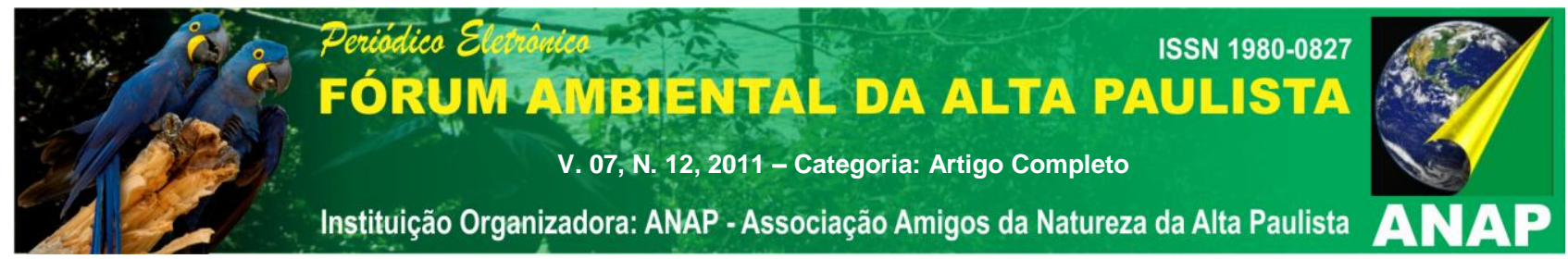

$1 \mathrm{NH}_{4}{ }^{+}+1,32 \mathrm{NO}_{2}{ }^{-}+0,066 \mathrm{HCO}_{3}{ }^{-}+0,13 \mathrm{H}^{+} \rightarrow 1,02 \mathrm{~N}_{2}+0,26 \mathrm{NO}_{3}{ }^{-}+0,066 \mathrm{CH}_{2} \mathrm{O}_{0,5} \mathrm{~N}_{0,15}+$ $2,03 \mathrm{H}_{2} \mathrm{O}$

(Eq. 4)

Tais bactérias apresentam morfologia de cocos com diâmetro menor que $1 \mu \mathrm{m}$ (VAN NIFTRIK et al., 2004), tempo de duplicação de aproximadamente 11 dias e são fisiologicamente distintas, pois são anaeróbias e quimiolitoautótrofas. Contêm uma organela ligada à sua membrana celular, a qual é responsável pela conversão do amônio e do nitrito a gás nitrogênio sob a ação da hidrazina $\left(\mathrm{N}_{2} \mathrm{H}_{4}\right)$ (KARTAL et al., 2010).

Quanto às características operacionais ótimas para o desenvolvimento dessa microbiota, pode-se dizer que o pH ideal para crescimento dos microrganismos está entre 7 e 8 com o ótimo próximo de 8 e a temperatura de atuação está na faixa de 20 a $43^{\circ}$ com o ótimo em $40 \pm 3{ }^{\circ} \mathrm{C}$ (SCHIERHOLT NETO, 2007). Ainda segundo Schierholt Neto (2007), o processo Anammox sofre forte inibição pela presença de oxigênio dissolvido (OD), mesmo em baixas concentrações como $2 \mu \mathrm{mol} / \mathrm{L}\left(0,06 \mathrm{mgO}_{2} \mathrm{~L}^{-1}\right)$. Porém, a inibição cessa imediatamente após a retirada do OD do meio sendo, portanto, uma inibição reversível.

Uma desvantagem deste tipo de tratamento é que o desenvolvimento de bactérias é muito lento e, portanto, é necessário um sistema eficiente de separação de sólidos e um longo período de partida para se obter a concentração de biomassa suficiente para uma boa operação (JETTEN et al., 1997).

A Figura 1 mostra um esquema do ciclo biológico do nitrogênio com o processo de nitrificação, desnitrificação, fixação do nitrogênio e Anammox.

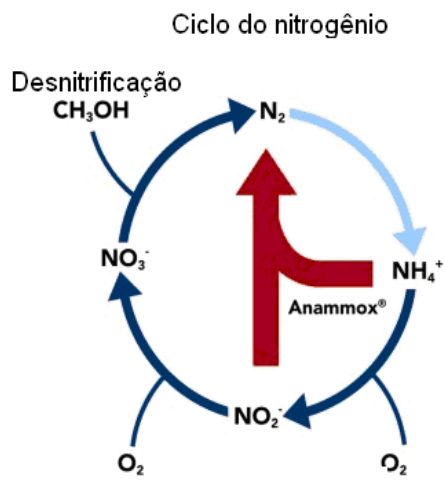

Figura 1 - Esquema representativo do ciclo biológico do nitrogênio.

Fonte: http://www.paques.nl/?pid=46 


\section{Materiais e Métodos}

\subsection{Sistema Reator Biológico Anammox}

O reator foi confeccionado com um tubo vidro (de $0,95 \mathrm{~m}$ de altura e diâmetro interno de $7,4 \mathrm{~cm}$ ) e com conexões e válvulas tipo PVC, operando em fluxo hidráulico vertical ascendente, onde o afluente é introduzido pela parte inferior, fluindo através da camada filtrante (material suporte) até o topo do reator (saída). Deste modo, o volume total do sistema em questão é de 4,18 L. Para o funcionamento deste reator foi utilizada uma única bomba peristáltica (modelo 85MHP5, marca STENNER), para que assim o afluente e efluente possuam a mesma vazão, permitindo que o nível do líquido permaneça constante dentro do reator. No sistema, foram empregadas duas mangueiras diferentes, uma com diâmetro igual a 1/4" (afluente) e a outra, com diâmetro de 5/," (efluente); sendo esta última conectada ao reator através de um extravasor. Foi colocado também, um tanque de armazenamento com capacidade de $1 \mathrm{~L}$ para introdução e recirculação do meio de cultivo no reator. As dimensões do reator são: 60,0 centímetros de altura preenchido com material suporte (leito fixo) para as bactérias Anammox; e 35,0 centímetros de headspace, sendo o diâmetro interno igual a 7,4 centímetros.

De forma a possuir controle sobre a temperatura, o reator foi fixado com um suporte metálico dentro de uma câmara de madeira com dimensões iguais: 1,50 metros de altura x 1,00 metro de largura x 1,00 metro de comprimento e monitorada através de um termostato digital que mantém a temperatura de $37 \pm 2^{\circ} \mathrm{C}$, buscando assim, minimizar os efeitos de possíveis variações de temperatura no sistema.

Manteve-se uma vazão de 0,9643 L.h ${ }^{-1}$ de amostra circulando pelo sistema, e o leito do material suporte é fixo, caracterizado pela presença de um material de empacotamento estacionário formado por partículas de pedriscos de formato granulado (diâmetro médio de $3 \mathrm{~mm}$ e massa específica igual a 2,60 g.cm ${ }^{-3}$ ), no qual os sólidos biológicos podem aderir ou ficar retidos nos interstícios (CHERNICHARO, 1997).

Dessa maneira, a massa de microorganismos manter-se-á aderida ao material suporte, degradando o substrato contido no fluxo do meio de cultura sintético. Esse meio de cultura sintético fornece nutrientes necessários para o cultivo de microrganismos fora de seu ambiente natural, e adotou-se o meio de cultivo sintético utilizado por Martins 


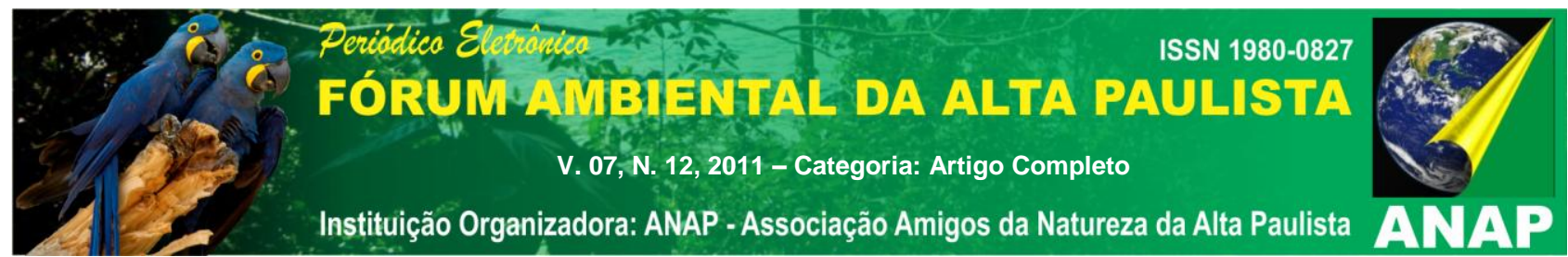

(2007) por apresentar a associação qualitativa e quantitativa de substâncias que propiciam o cultivo de bactérias Anammox.

Como inóculo, utilizou-se $225 \mathrm{~mL}$ do lodo proveniente de uma lagoa de estabilização anaeróbia de um abatedouro de bovinos situado no município de Presidente Prudente/SP. Este tipo de lodo foi escolhido com o objetivo de verificar a presença de bactérias anaeróbias oxidadoras de amônia e devido a grande presença de nitrogênio amoniacal (Tabela 2).

Tabela 2 - Características físico-químicas médias do efluente bruto disposto na segunda lagoa de estabilização do batedouro de bovinos.

\begin{tabular}{cc}
\hline Parâmetros & Valor \\
\hline DQO & $10005,33 \mathrm{mg} \cdot \mathrm{L}^{-1}$ \\
DBO & $165,90 \mathrm{mg} \cdot \mathrm{L}^{-1}$ \\
Nitrogênio Amoniacal & $221,48 \mathrm{mg} \cdot \mathrm{L}^{-1}$ \\
Nitrito & $7,25 \mathrm{mg} \cdot \mathrm{L}^{-1}$ \\
Nitrato & $2,13 \mathrm{mg} \cdot \mathrm{L}^{-1}$ \\
OD & $0,43 \mathrm{mg} \cdot \mathrm{L}^{-1}$ \\
pH & 7,26 \\
\hline
\end{tabular}

\subsection{Análises Físico-Químicas Realizadas}

A metodologia empregada para as análises físico-químicas desta pesquisa é baseada nos procedimentos do Standard Methods for the Examination of Water and Wastewater (APHA/AWWAMEF, 1998), sendo que as amostras de efluente bruto foram retiradas do reservatório e, as amostras de efluente tratado, da parte superior do reator (acima do meio suporte). No projeto em questão, são feitas análises de: Demanda Química de Oxigênio (DQO), Nitrogênio Amoniacal, Nitrito, Nitrato, Oxogênio Dissolvido (OD), pH e Termogravimetria (TG).

\subsection{Monitoramento do Sistema}

Após a inoculação do sistema com $225 \mathrm{~mL}$ de lodo proveniente da indústria de abate e a posterior recirculação dentro do reator de 1 litro de meio de cultivo sintético 


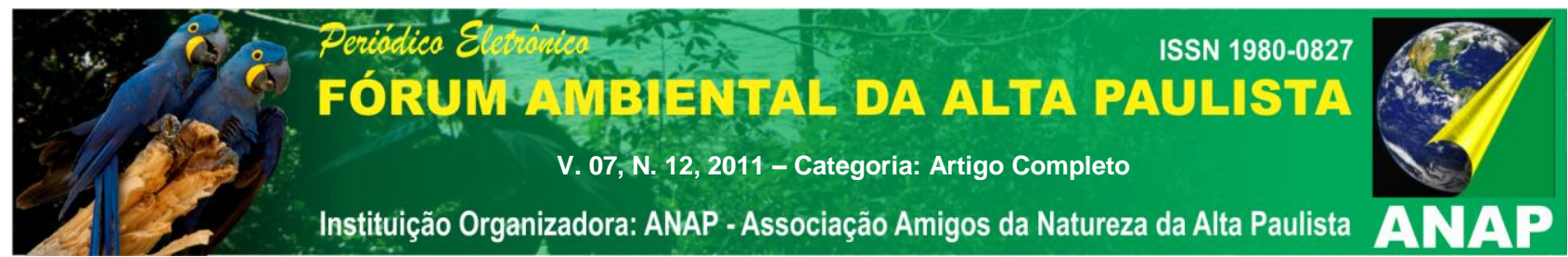

misturado a um volume de, aproximadamente, 5 litros de efluente bruto da mesma indústria durante um período de 14 dias (período no qual foram efetuadas apenas as medições de OD e acompanhamento da temperatura), houve a definitiva partida do reator, pelo descarte completo desta mistura e sua substituição por meio de cultivo, exclusivamente. Assim era adicionado a cada nova batelada um volume de 1 litro de meio de cultivo sintético. No entanto, ressalta-se que somente o volume de líquido presente no tanque de armazenamento era substituído, evitando ao máximo prejudicar a retenção de biomassa bacteriana no interior do reator.

A partir deste momento, em todas as bateladas foram monitoradas as concentrações de nitrogênio amoniacal, nitrito e nitrato com o intuito de coletar dados para cálculo dos coeficientes estequiométricos da reação química que rege o processo Anammox. Com o objetivo de analisar a disponibilidade de matéria orgânica no sistema, também monitorou-se o comportamento da DQO durante as bateladas. O tempo de duração das bateladas foi estabelecido de acordo com a eficiência de remoção de $\mathrm{N}$ $\mathrm{NH}_{4}{ }^{+}$, assim, toda vez que era constatada uma concentração de $\mathrm{N}-\mathrm{NH}_{4}{ }^{+}$abaixo de 50 $\mathrm{mg} \cdot \mathrm{L}^{-1}$, era descartado o líquido para introdução de um novo meio de cultivo no reator.

A Tabela 3 traz informações a respeito da duração das bateladas.

Tabela 3 - Informações sobre as bateladas.

\begin{tabular}{cc}
\hline № da Batelada & Duração (dias) \\
\hline 1 & 9 \\
2 & 5 \\
3 & 7 \\
4 & 5 \\
5 & 5 \\
6 & 5 \\
\hline
\end{tabular}

Além disso, foi calculado o Tempo de Detenção Hidráulica (TDH) que representa o tempo médio de permanência das moléculas de água em uma unidade de tratamento que é alimentada continuamente. Para o cálculo do TDH foram usados os seguintes parâmetros: vazão da bomba $(\mathrm{Q})$ e volume de líquido no reator $\left(\mathrm{V}_{\mathrm{R}}\right)$, de acordo com a Equação 5: 


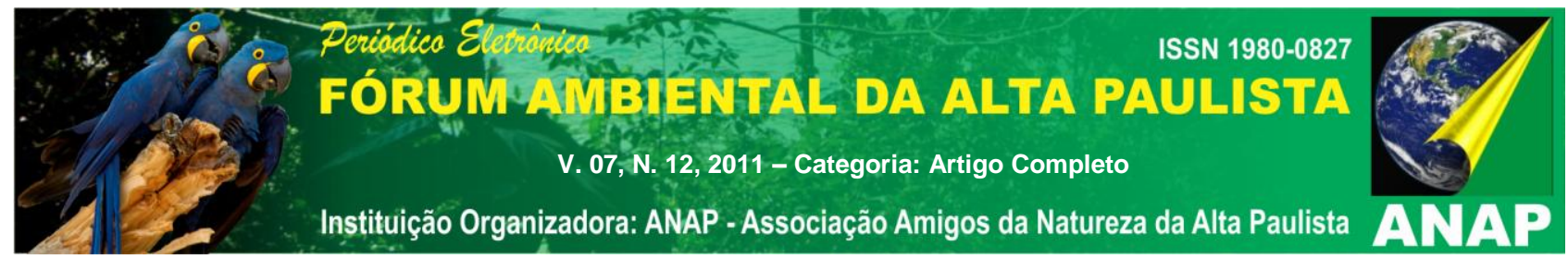

$$
\begin{aligned}
& \mathrm{TDH}=\mathrm{V}_{\mathrm{R}} / \mathrm{Q} \\
& \mathrm{V}_{\mathrm{R}}=\mathrm{V}_{1}+\mathrm{V}_{2}
\end{aligned}
$$

$\mathrm{Na}$ Equação 6, tem-se que $\mathrm{V}_{1}$ representa o volume de líquido na parte cilíndrica do reator e $V_{2}$, o volume de líquido na região cônica (parte inferior do tubo de vidro). Lembrando que, para se obter $\mathrm{V} 1$, foi levado em consideração o fato de que na região com meio de suporte, $60 \%$ do volume corresponde aos pedriscos. Como a altura de líquido dentro do reator foi fixada em $13 \mathrm{~cm}$ acima do nível de lodo, para se obter o tempo de detenção hidráulica, considerou-se que a altura total de líquido no reator $\left(H_{R}\right)$ corresponde a altura de $60 \mathrm{~cm}$ preenchida com pedriscos somada à altura de $2 \mathrm{~cm}$ correspondente ao lodo e aos $13 \mathrm{~cm}$ de líquido, ou seja, $\mathrm{H}_{\mathrm{R}}=75 \mathrm{~cm}$.

\section{Resultados Preliminares}

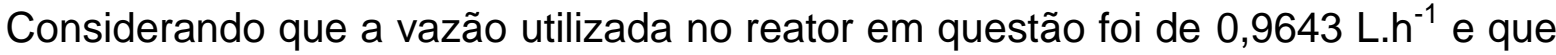
o volume de líquido circulando no reator, após a retirada do tanque de armazenamento foi de 1,69 L, o TDH estabelecido foi de 1,753 h.

\subsection{Remoção e Produção de Compostos Nitrogenados}

As Figura 2, 3 e 4 mostram, respectivamente, todos os resultados obtidos nas bateladas em que foram realizadas as leituras do meio de cultivo "bruto" (afluente) e outra do "tratado" (efluente) para concentrações de nitrogênio amoniacal, nitrito e nitrato das amostras.

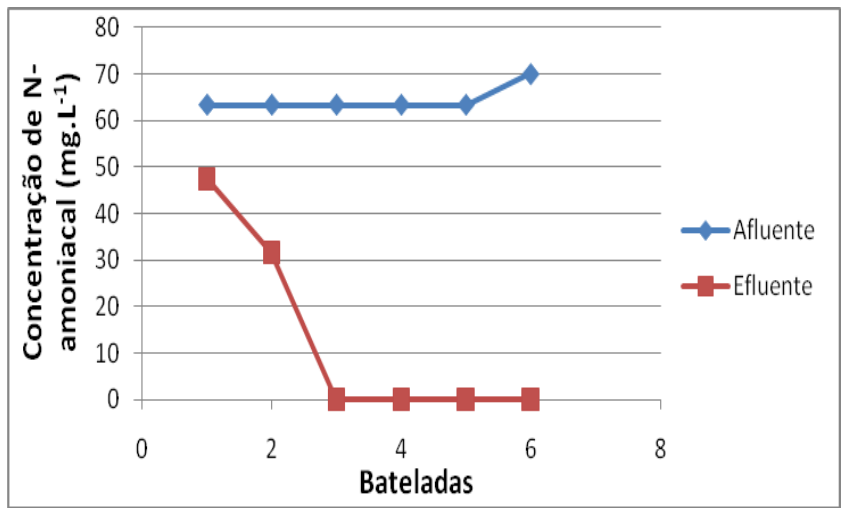

Figura 2 - Variação das concentrações afluente e efluente de nitrogênio amoniacal durante as seis bateladas realizadas.

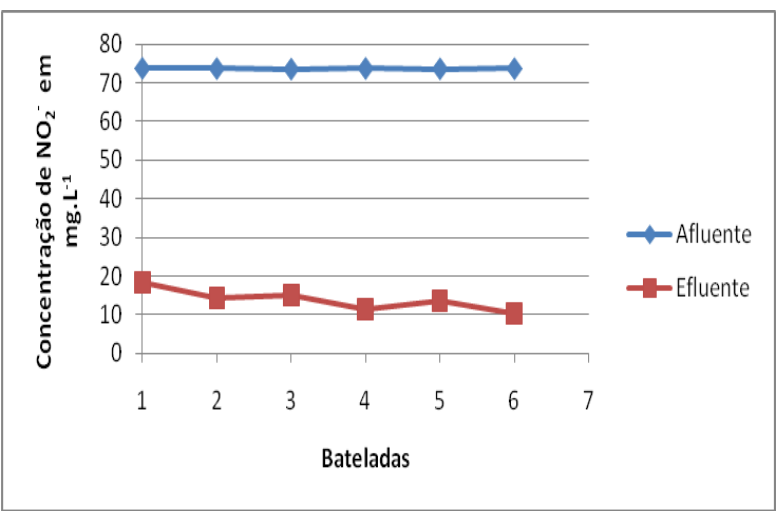

Figura 3 - Variação das concentrações afluente e efluente de nitrito durante as seis bateladas realizadas. 

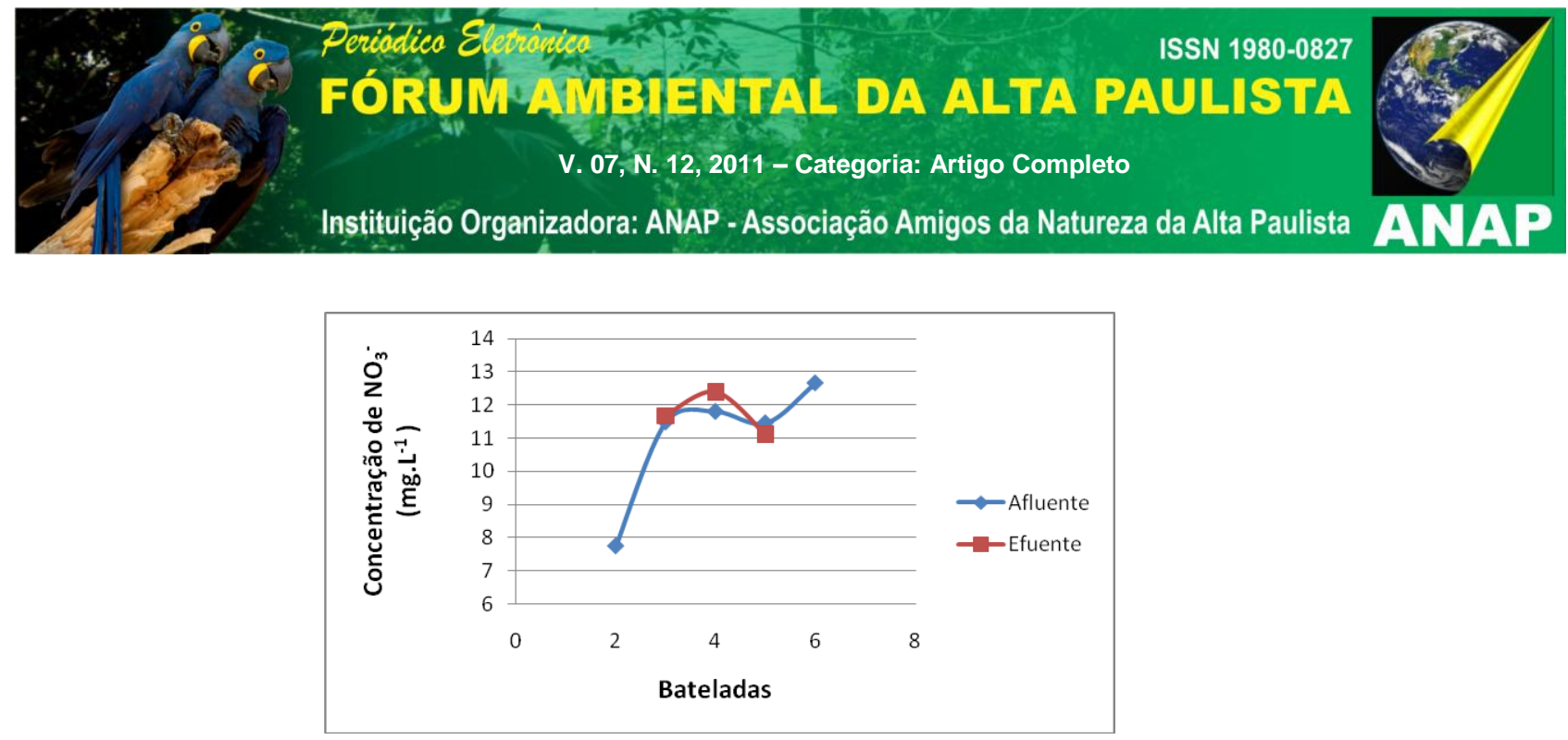

Figura 4 - Variação das concentrações afluente e efluente de nitrato durante as seis bateladas realizadas.

Observando a Figura 2, nota-se que durante todo o tempo de operação do sistema houve remoção de nitrogênio amoniacal. Nas duas bateladas inicias esta remoção foi um pouco menos expressiva (uma média de $37,5 \%$ de remoção para o período), porém a partir da 3a batelada a remoção deste composto foi de $100 \%$, seguindo neste ritmo até o final (50ํ dia de operação).

Pela análise da Figura 3, se vê que ocorre um decréscimo de nitrito nas amostras efluentes de meio de cultivo. O consumo de nitrito pode indicar que há condições para que o processo Anammox ocorra, pois de acordo com a Figura 1 as bactérias fazem este processo transformando nitrito e amônia em nitrogênio gasoso.

Já com relação ao nitrato (Figura 4), percebe-se o meio de cultivo apresenta concentrações afluentes e efluentes em mesmo nível, uma vez que o meio de cultura adotado tem em sua composição a adição de outros compostos que podem ser oxidados facilmente à nitrato. Devido à problemas técnicos o monitoramento de nitrato efluente foi prejudicado, porém ainda assim pôde-se perceber uma tendência a formação até a $4^{a}$ batelada. Abaixo segue o gráfico representativo da variação de oxigênio dissolvido no reator segundo o andamento das bateladas.

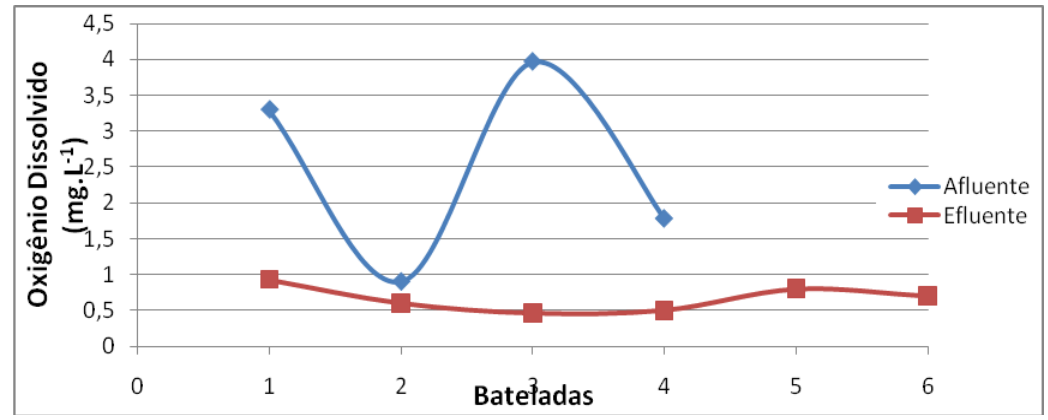

Figura 5 - Variação das concentrações de oxigênio dissolvido durante as seis bateladas realizadas. 


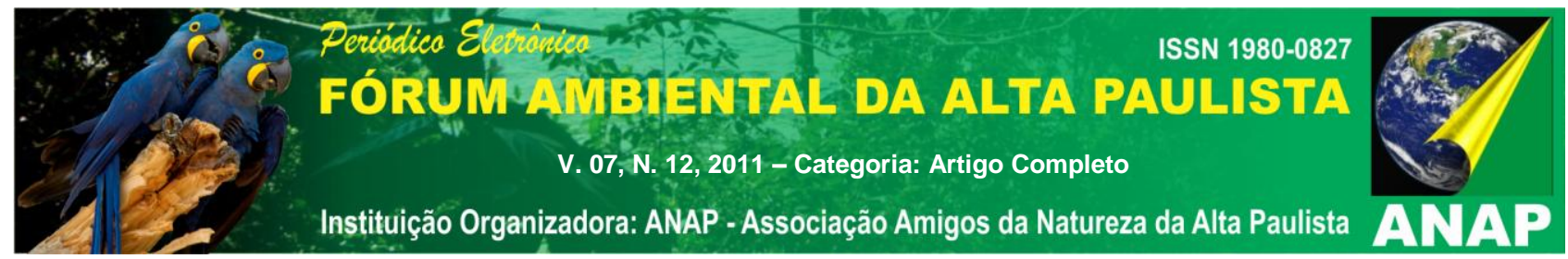

Verifica-se a presença do tanque de armazenamento até a batelada 4, o qual servia como fonte para a contaminação por OD no interior do reator. Posteriormente, com a retirada deste compartimento, nota-se uma tendência de se estabelecer um equilíbrio na concentração baixa de oxigênio no efluente.

Outro parâmetro que também foi monitorado a partir da $2^{\mathrm{a}}$ batelada é a DQO, cujo gráfico está representado abaixo.

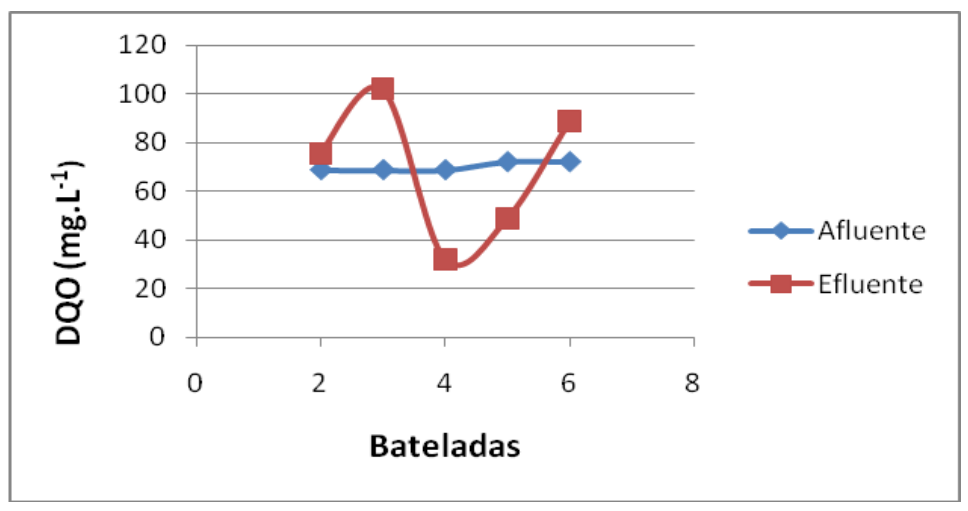

Figura 6 - Comportamento da DQO durante as seis bateladas realizadas.

Através da Figura 6, observa-se que a retirada de oxigênio dissolvido dentro do reator na 4⿳亠丷厂 batelada também influenciou na disponibilidade de matéria orgânica no sistema, uma vez que nas bateladas seguintes, o índice de remoção de DQO foi ficando cada vez menor até não existir mais sua remoção a partir da $6^{\underline{a}}$ batelada. Isto é muito interessante para o desenvolvimento das bactérias Anammox, pois indica que as bactérias oxidadoras aeróbias não têm uma fonte de carbono presente, ou seja, não há de onde elas obterem a energia para sua atividade biológica. A ausência de remoção de DQO na $2^{\underline{a}}$ e $3^{\underline{a}}$ batelada pode ser explicada pela disponibilidade de matéria orgânica ainda presente no reator, vinda do efluente bruto do frigorífico, o qual apresenta uma concentração de matéria orgânica elevada, como mostrado na caracterização do efluente (Tabela 2).

\subsection{Análises Térmicas}




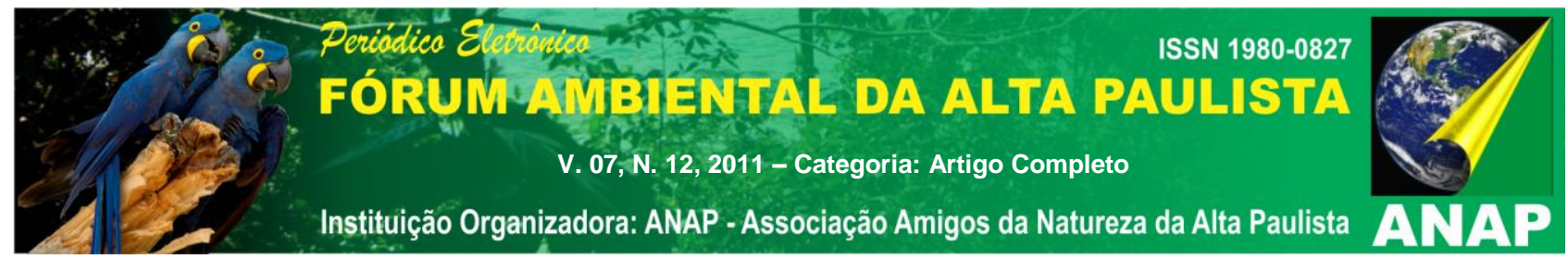

Primeiramente, analisaram-se os pedriscos limpos, ou seja, aqueles que foram inicialmente introduzidos no sistema reator, com o intuito de criar um parâmetro de comparação para as demais amostras retiradas do sistema no decorrer do projeto. Os gráficos representados abaixo trazem, simultaneamente, as informações de perda de massa dos ensaios em duplicata.

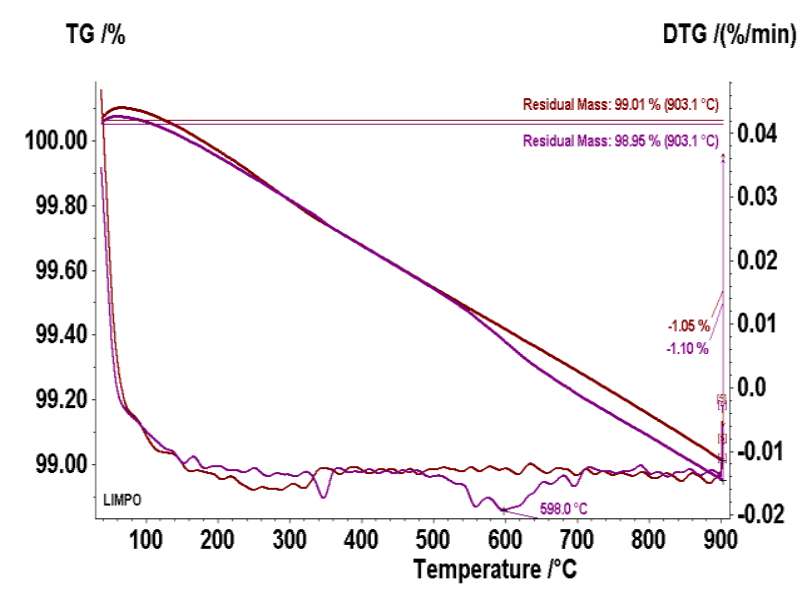

Figura 7 - Análise de tratamento térmico com o pedrisco limpo.

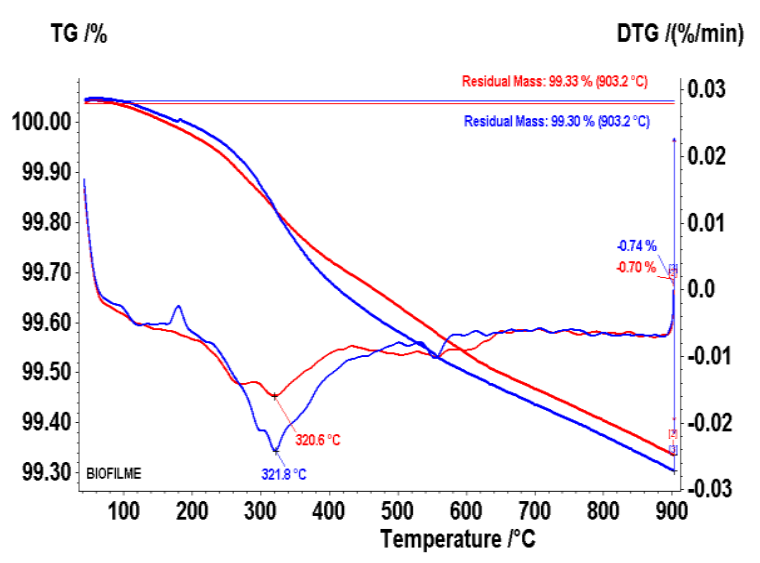

Figura 8 - Análise do tratamento térmico com o pedrisco retirado do reator no dia 10 de fevereiro de 2011.

Observando-se a Figura 7, pode-se notar que o pedrisco limpo, nos dois ensaios, não apresentou uma perda de massa significativa (1,05\% e 1,10\%) e que a mesma, por meio da observação das curvas das derivadas, aconteceu de forma contínua à medida que a temperatura no interior do aparelho aumentava.

Já pela análise da Figura 8, observa-se uma perda de massa um pouco menor do que as perdas do pedrisco limpo (correspondentes a 0,74\% e 0,70\%). Como foi utilizada uma massa ínfima de amostra inicial (aproximadamente 0,5 mg,) percebe-se que essa diferença de percentagem entre o pedrisco limpo e o que foi retirado do reator não é significante, já que podem ter ocorrido falhas na detecção da termobalança em ambos os ensaios, uma vez que esta funciona de modo apropriado e confiável na análise de massa superiores (próximas a $5 \mathrm{mg}$ ). Este resultado apenas indica que não houve retenção expressiva de biofilme numa massa mínima de meio suporte durante o período de 24 dias, contados a partir do início da fase de aclimatação do reator até a retirada do material suporte no dia 10 de fevereiro de 2011. 


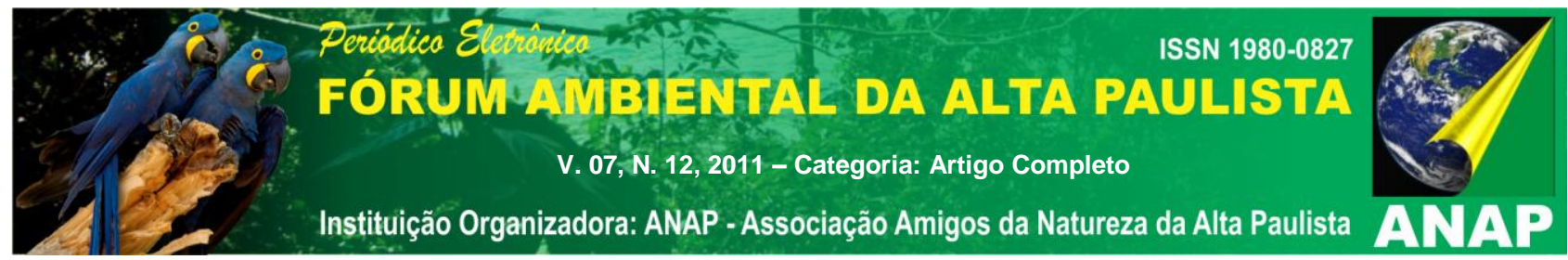

Porém, pela existência de pontos de mínimo bem evidentes nas curvas das derivadas conclui-se que a perda de massa neste caso não foi contínua; houve portanto, uma perda de massa concentrada em uma faixa de temperatura próxima a $300^{\circ} \mathrm{C}$, zona caracterizada pela queima preferencial de matéria orgânica. Ou seja, pode-se induzir que há vestígios de matéria orgânica agregados ao meio suporte, no entanto este ainda não atingiu um peso suficientemente significativo para influenciar na percentagem total de perda de massa.

Além disso, pode ser que durante a retirada do material para as análises térmicas tenha ocorrido a colisão deste com os demais grãos e até mesmo com as paredes do sistema, ocasionando um desprendimento de biofilme. De acordo com Gjaltema et al. (1997), o desenvolvimento do biofilme é determinado pelo equilíbrio entre crescimento e desprendimento de biomassa; a alteração deste equilíbrio interfere na espessura do biofilme. O desprendimento do biofilme pode ser provocado por colisões do meio suporte com as paredes entre si, por tensões de cisalhamento e por borbulhamento de gás.

\section{Conclusões}

Diante a todas as informações obtidas na execução desta pesquisa, conclui-se que através da análise dos resultados obtidos durante os 50 dias de operação do reator biológico ainda não pode ser verificada se a remoção anaeróbia de nitrogênio amoniacal foi por meio de bactérias Anammox. Houve uma redução completa deste composto a partir da $3^{\text {a }}$ batelada, porém esta pode ter sido realizada pelas bactérias aeróbias nitrificantes.

A partir da 4⿳亠丷a batelada foram feitas algumas mudanças no sistema reator, de maneira que a concentração de oxigênio dissolvido pôde ser reduzida e controlada, favorecendo assim, o processo de oxidação de N-amoniacal pela via Anammox. Isto pôde ser observado pelo consumo do nitrito afluente e pela propensão de diminuição de nitrato nas bateladas, criando condições no interior do reator para o desenvolvimento da cultura Anammox.

Pelos ensaios de termogravimetria, foi possível detectar vestígios de matéria orgânica agregados ao meio suporte retirado do reator, uma vez que a perda de massa ficou concentrada numa zona caracterizada pela queima exclusiva de matéria orgânica. 


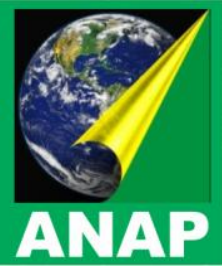

\section{Referências Bibliográficas}

APHA. Standart Methods - For the examination of water and wastewater, 1998.

BOAVENTURA, R.A.R.; RODRIGUES, A.E. Denitrification kinetics in a rotating disk biofilm reactor. Chemical Engeneering Journal, v.65, n. 3, p.227-235, 1997.

BRASIL. Lei federal no 9.433, de 08 de janeiro de 1997. Institui a Política Nacional de Recursos Hídricos, Cria o Sistema Nacional de Gerenciamento dos Recursos Hídricos, regulamenta o inciso XIX do artigo 21 da CF, e altera o artigo 1 da Lei 8.001 de 13.03.1990 que modificou a Lei 7.990, de 28.12.1989. Diário Oficial da República Federativa do Brasil, Brasília, DF, 09. jan.1997. Disponível em: www.mma.gov.br. Acesso em: 06 de janeiro de 2011.

BRASIL. Ministério do Meio Ambiente, Conselho Nacional do Meio Ambiente, CONAMA. Resolução CONAMA n 357, de 17 de março de 2005 In: Resoluções, 2005. Disponível em: www.mma.gov.br. Acesso em: 20/03/2011.

BRITO, R. M.; GARCIA, G. C. P.; Otimização do rendimento de um reator seqüencial por batelada para o tratamento de efluentes de indústria de refrigerantes. 2008. Monografia. Faculdade de Ciências e Tecnologia, Universidade Estadual Paulista, Presidente Prudente.

CHERNICHARO, C. A. L. Reatores Anaeróbios. 1997. 246f. Departamento de Engenharia Sanitária e Ambiental, Universidade Federal de Minas Gerais, Belo Horizonte. COOD, G.A.; MORRISON, L.F.; METCALF, J.S. Cyanobacterial toxins: risk management for health protection. Toxicol. Appl. Pharmacol, p. 264-272, 2005.

EPA. Development Document for the Proposed Effluent Limitations Guidelines and Standards for the Meat and Poultry Products Industry Point Source Category ( 40 CFR 432). Office of Water Mail Code 4303 T. Washington, DC, Jan., 2002.

GJALTEMA, A; VINKE, J.L.; VAN LOOSDRECHT, M.C.M.; HEIJNEN, J.J. Abrasion of suspended biofilm pellets in airlift reactors: Importance of shape, structure and particle concentrations. Biotechnology Bioengineering. v. 53, p. 88 - 99, 1997.

JETTEN, M.S.M.; HORN, S.J.; VAN LOOSDRECHT, C.M. Towards a more sustainable municipal wastewater treatment system.Water Science \& Tecnology, v.35, p. 171-180, 1997.

KARTAL, B., KUENEN, J.G.,VAN LOOSDRECHT, M.C.M. Sewage 


\section{Periódica $\&$ \\ FÓRUM-AMB̈J \\ V. 07,N. 12, 2011 - Categoria: Artigo Completo \\ Instituição Organizadora: ANAP - Associação Amigos da Natureza da Alta Paulista}

treatment with Anammox. Science. v. 328. p.702-703, 2010.

KHIN, H.; ANNACHHATRE, A.P. Novel microbial nitrogen removal processes. Biotechnology Advances, v.22, p.519-532, 2004.

KUIPER-GOODMAN, T.; FALCONER, I.; FITZGERALD, J. Toxic Cyanobacteria in Water: A Guide to their Public Healh Consequences, Monitoring and Management. W.H.O., Bury St. Edmonds, p. 113-154, 1999.

MADIGAN, T. M.; MARTINKI, J. M.; PARKER, J. Brock bilology of microorganisms. Prentice Hall, Inc., 8a. Edição, N.Y., 1997.

MARTINS, T. H. Enriquecimento de Consórcios Microbianos em Quimiostatos sob

Condições Anammox. 2007. 60 f. Dissertação (Mestrado em Hidráulica e Saneamento). Escola de Engenharia de São Carlos, Universidade de São Paulo.

METCALF \& EDDY. (2003). Wastewwater Engineering: Treatment, disposal and reuse. McGraw Hill, 4ํㅡㄹ., N. Y., 1819 p.

SCHIERHOLT NETO, G. F. Desenvolvimento de Uma Flora de Microrganismos Oxidadores Anaeróbios de Amônia Utilizando Inóculos Provenientes de Dejeto de Suíno. 2007. 101 f. Dissertação (Mestrado em Engenharia Química). Universidade Federal de Santa Catarina, Florianópolis.

STROUS, M.; FUERST, J.; KRAMER, E.; LOGEMANN, S.; MUYZER, G.; VAN DE PAS, K.; WEBB, R.; KUENE, J.; JETTEN, M.S.M. Missing lithotroph identified as new planctomycete. Nature, v. 400. p. 446-449, 1999.

VAN DE GRAAF, A.A.; BRUIJN, P.; ROBERTSON, L.A.; JETTEN M.S.M.; KUENEN, J.G. Autotrophic growth of anaerobic ammonium-oxidizing micro organisms in a fluidized bed reactor. Microbiology, v. 142. p. 2187-2196, 1996.

VAN NIFTRIK, L.A. et al. The anammoxosome: an intracytoplasmic compartment in anammox bacteria. FEMS Microbiology Letters, v. 233, n. 1, p. 7-13, 2004. 